\title{
Seeing and inviting participation in autistic interactions
}

\author{
Hanne De Jaegher', 2 \\ ${ }^{1}$ Senior Researcher, LAS-Research Centre for Life, Mind \& Society, \\ Department of Philosophy, University of the Basque Country, Spain \\ ${ }^{2}$ Visiting Fellow, ChatLab, School of Psychology, University of Sussex, UK
}

\begin{abstract}
What does it take to see how autistic people participate in social interactions? And what does it take to support and invite more participation? Western medicine and cognitive science tend to think of autism mainly in terms of social and communicative deficits. But research shows that autistic people can interact with a skill and sophistication that are hard to see when starting from a deficit idea. Research also shows that not only autistic people, but also their nonautistic interaction partners can have difficulties interacting with each other. To do justice to these findings, we need a different approach to autistic interactions-one that helps everyone see, invite, and support better participation.
\end{abstract}

I introduce such an approach, based on the enactive theory of participatory sense-making and supported by insights from indigenous epistemologies. This approach helps counteract the homogenising tendencies of the "global mental health" movement, which attempts to erase rather than recognise difference, and often precludes respectful engagements. Based in the lived experiences of people in their socio-cultural-material and interactive contexts, I put forward an engaged_-even engaging — epistemology for understanding how we interact across difference. From this perspective, we see participatory sense-making at work across the scientific, diagnostic, therapeutic, and everyday interactions of autistic and non-autistic people, and how everyone can invite and support more of it.

Keywords: autism, double empathy, enactive approach, indigenous epistemology, participatory research, engaged epistemology, participatory sense-making, linguistic bodies 


\section{Between a fishbowl and an imitation game}

What does it take to see how autistic people participate in their social interactions - among themselves and with non-autistics? And what does it take to invite and support more and better participation, if, when, and as desired and appropriate? ${ }^{1}$

If we engage badly with someone or something we are trying to understand, we may misunderstand and potentially damage them. This regularly happens with autistic people, and with autism as a topic. Damian Milton, an autistic autism researcher, writes that approaches to autism "often [lead] to ill-fated attempts at normalisation and a continuing vicious cycle of psycho-emotional disablement" (2014, p. 799). This happens because the lived experiences of autistic people are often taken as deficient and as not relevant or interesting in their own right (Yergeau 2018, Hens 2019, Jaswal and Akhtar 2019).

It happens for instance when autistic people are taught the 'rules of social interaction,' as part of one or another 'remedial program'. For example, autistic children are 'taught' to make eyecontact by conditioning them. But it is well known that making eye-contact can be painful for autistic people (Schaber 2014). ${ }^{2}$ Teaching them to make eye-contact ignores-even goes against - the needs and sensitivities of many autistic people. This example in the realm of practice has its counterpart in psychological theories about autism, such as the Theory of Mind (ToM) theory, which suggests autistic people have difficulty reading other people's minds (Baron-Cohen et al. 2013). Such theories are objectivist and individualistic, and start from a detached view of the human psyche and social world. Because of this, these theories preclude us from seeing autistic people's engagement. Teaching people (autistic or not) the 'rules' of social interaction does not tend to lead to improved social fluency (Ozonoff and Miller 1995; Koenig et al. 2009).

This is because our social capacities cannot be captured in abstract rules about how to interpret and predict others' behaviours. Instead, social expertise is based in the lived experience of the social interactions we engage in from very early in life (Trevarthen and Aitken 2001, Reddy 2008, 2012, Zlatev et al. 2008, Lymer 2011, Di Paolo and De Jaegher 2012). Since ToM is about interpreting and predicting behaviours and ignores the significance of connecting and interacting, it may in fact reinforce the "fragmented social perceptions" of autistic people "via the very way 'social skills' are being taught" (Milton 2014, p. 798). A better approach is to begin from the capacities, even if limited, that an autistic person has, and to build up from there, in and through activities of relating, such as imitation and child-led play (Caldwell 2006, Nind and Hewitt 1994, Nind and Powel 2000, see also Gernsbacher 2006).

There is a high need for better recognition of autistic people and their capacities, needs, desires and struggles. But as Jessica Benjamin (1988) shows, recognition is two-sided, and comes with high stakes in interaction. While engaging, we not only recognise an other. We are ourselves recognised, with all the risks this involves. Really engaging with autistic people thus provides us with more than a mirror in which we become aware of ourselves and our approaches. We cannot avoid being transformed by how we know autism. This is as true for carers, researchers,

\footnotetext{
${ }^{1}$ That is, while also recognizing and heeding the wishes of autistic people (and non-autistics too) to not always have to interact (Fletcher-Watson and Crompton 2019, see also Reddy 2008, Kyselo 2014, Galbusera et al. 2019).

2 At the same time, making eye-contact is not such a universal "social rule" as we might think (see Zhang et al. 2006 and LeVine et al. 1994, quoted in Jaswal and Akhtar 2019).

Accepted for publication in Transcultural Psychiatry, July 2020 (this is the before-proof version) 
psychiatrists, as it is for autistic people and their family, friends, therapists, teachers, colleagues. In all of these capacities, we engage and interact with each other. Lack of engagement can literally make us misunderstand each other (see e.g. Maddox et al. 2019, also Fletcher-Watson et al. 2018).

Milton (2012) has diagnosed what he calls a double empatby problem, pointing precisely to difficulties in understanding that both sides have, allistics (i.e. non-autistic people) as much as autistics. Not seeing this, and-paradoxically? — expecting autistic people to do all the work of making interactions better, results in "a lack of interactional expertise between researchers and autistic people[,] a breakdown in trust and communication [and] an increase in tension between stakeholder groups" (Milton 2014, p. 800).

I agree with this, and also with Milton's recommendation, shared by many autistic people and by more and more researchers, that, in order for research on autism to "claim ethical and epistemological integrity," we need to stop "fishbowling" people with autism (Milton and Moon 2012). Instead, we need greater "involvement of autistic scholars in research and improvements in participatory methods" (Milton 2014, p. 794). There is a lot of development and promotion of participatory research (see e.g. Pellicano et al. 2017, Fletcher-Watson et al. 2019, Nicolaidis et al. 2019), but it is also being criticised by some autistic researchers for carrying its own risks of being exclusionary.

My question in this paper is: How can we best understand the lived experience of the dynamics of participation, so that participatory research methods most benefit autistic people, and everyone's understanding of autism?

Milton (2014) puts forward an approach to furthering the involvement of autistic researchers in autism research, as well as engagement between autistic and non-autistic people more generally. Building on sociologist Harry Collins's concept of “interactional expertise" (Collins and Evans 2007), Milton proposes a kind of imitation game to test whether a researcher understands autistic people enough to speak about or for them. To see if someone has the ability "to engage and interact with autistic language and communications" (Milton 2014, p. 796), they should show a capacity to imitate being autistic, such that independent judges could not distinguish them from an autistic person.

But this kind of test is problematic. The first question, raised by Milton himself, is whether it is possible to have full imitative expertise of someone else in the case of (high) neurological difference (such as, supposedly, between an autistic and a non-autistic person). He even wonders whether "some level of expertise in what it is to be autistic on a phenomenological level of lived experience [is] always beyond the grasp of non-autistic social scientific researchers" (Milton 2014, p. 799). In some sense, I think it is. But neither the lived experience nor the expertise at work here are fixed, as we will see.

There is a second question we must ask. To show that we understand someone, do we really need to imagine or pretend to be so much like them that we become practically indistinguishable from them? If we were to become so much like the other, to the point of becoming them, we would coincide with them. And this, in fact, makes us lose both the other, and ourselves.

But not only this. In so doing, we also lose the possibility to, precisely, interact with each other. Interacting, engaging, requires that we remain separate. It is only as people who are different but interested in engaging that we can interact. And it is only in such interactions-between people 
who are different but interested in each other - that we can get to know each other, both in life and scientifically (Reddy 2008).

I know this last point, that we need difference, interest, and engagement for gaining scientific knowledge, is contentious. A received criterion of rigour in Western science demands that we gain knowledge only from an indifferent, disinterested, detached stance. However, it has been well established that understanding knowledge in this way is an illusion (see, e.g., Polanyi 1958, Prigogine and Stengers 1984, Césaire 1990, Meek 2011). But not only that. Understanding knowledge like this can be actively harmful. One area where this shows is precisely autism research. By "scientifically" interacting with autism, i.e. with an objective-really: remotestance, we contribute to the alienation of autistic people. We could even be accused of instituting alienation. This is what the neurodiversity movement acts against (Singer 1999, Davidson and Orsini 2013, Walker 2017, Woods et al. 2018, Kapp 2020, Milton et al. 2020). Started in the autistic civil rights movement, neurodiversity counters the idea of one standard, "normal" way of being and thinking, and instead advocates for understanding the neurological diversity that characterises the human population as a whole. We are all different, and all deserve respect in our differences. The dominance of colonial Western scientific thinking is not only contested by autistic people, but by many others as well, not in the least by indigenous people across the world. Indigenous epistemologies can be said, in general — though they are varied and variously differ from each other-to start from an engaged worldview. They tend to aim for a harmonious interaction between individual people's development and communal and cosmic harmony. One of the backgrounds I weave into this paper brings together arguments of critical autism studies and the neurodiversity movement with indigenous epistemologies. I do this because they share a striving against the (psychiatric) othering of colonial approaches, and for respect across difference.

For all these reasons, what I will argue for and work to better understand in this paper is interested engagement.

My aim is double: I want to contribute to better seeing the kinds of participation that are already there in the interactions of autistic people, and to invite more of it, in accordance with the needs, questions, wishes, struggles and strengths of everyone involved in each concrete situation. I will do this on the basis of a cognitive science paradigm that is precisely concerned with understanding human interaction in this humane way-one that does justice to human intersubjective experience. This is the enactive approach to cognition.

Enaction is a paradigm in cognitive science that begins from the needs of living beings, their situated and bodily experiences, and the ways they engage with each other, to understand how they make sense of the world and each other. I introduce this approach in sections 2 and 3 , while also expanding it with insights from indigenous epistemologies. ${ }^{3}$ In section 4 , we will look at some examples from autistic languaging and interacting through the lens of this enriched enactive approach, and implications for transcultural psychiatry.

What runs through all this, both in practice and in theory, are threads and difficulties of engagement. The current changes in our understanding of autism and in the scientific disciplines

\footnotetext{
${ }^{3}$ In a sense, in this paper, I make a beginning with such a connection between embodied, enactive cognitive science and indigenous epistemologies (see also De Jaegher 2019). Some indigenous researchers and researchers studying indigenous ways of knowing are, from their part, also opening up such a connection (see, e.g., Kincheloe 2011, Mejía-Arauz et al. 2018). This mutual reaching out to each other is a promising area for future research.
}

Accepted for publication in Transcultural Psychiatry, July 2020 (this is the before-proof version) 
and fields of practice involved in this lead to novel insights, but also to new tensions in engagement. The growing participation of autistic people in all aspects of research and the autistic self-advocacy movement open up not only exciting new questions, but also heated debates. One example is the question of which language to use to describe people with autism. Which way of speaking most helps autistic people live well, be themselves, and participate in society? The best thing to do is to ask them, and to be open, sensitive, and transparent about the issue. ${ }^{4}$ This is a good paradigm for autism research and for understanding and engaging in interactions with autistic people.

To be better able to cut through some of the complexities surrounding social interactions and autism, I think it is useful to see that what we are facing are tensions in letting each other be. Tensions, that is, in dealing with difference, from both sides, as Milton and others show. If, as scientists, therapists, teachers, medical doctors, we impose a certain understanding of autism on the people we are interacting with, they cannot be, in a particular sense. They cannot be themselves. This isand leads to-misunderstanding and harm. To change this, we need to better understand what respectful engagement is. Engagement, that is, in which we can all let each other be.

I have a particular meaning in mind of letting be. I do not mean by it an invitation to disengage. On the contrary, letting be refers precisely to the existential engagement that is at the heart of all our interactions - an engagement that involves us deeply, and that is as transformative of the being and becoming of whom we engage with, as it is of our own being and becoming. This is a difficult thing both to understand and to do. This is because it generates all kinds of tensions, of self-maintenance and of mutual influences and determinations.

To better understand autism and to better interact with each other, everyone will have to be able to stand on their own ground, to bring their own specific wishes and capacities, questions, troubles and hopes to the table_-autistic and non-autistic participants alike. The letting be that I am talking about here is an existential engagement. As such, it is at once epistemological, ontological, and ethical, and involves all interaction partners fully.

In what follows, I explain what this means based on Kym Maclaren's work in epistemology, insights from indigenous epistemologies, and the enactive approach to social understanding as participatory sense-making.

\section{A broken horse and epistemology}

How do we know something?

Philosopher Kym Maclaren says knowing has something to do with letting be (Maclaren 2002). What does this mean? Consider, she says, a horse trainer who is mainly interested in making money off of his horse. He trains and trains the animal, drills and exercises it. As this goes on, the horse becomes more and more damaged and dispirited. Eventually it breaks down.

\footnotetext{
${ }^{4}$ The best and first principle for deciding which language to describe people with is to ask them. Or, when the group is too big or there is disagreement, to use the ways of speaking that the majority prefers. At this place and time, while speaking in an anglophone academic literature, this seems to be identity-first language (Kenny et al. 2016). This is what I will use mostly here, sparsely interspersed with some person-first language (because there are also people who find that most respectful, even if they are not the loudest voices at the moment). Future readers and readers from different cultural and linguistic backgrounds may well have different preferences (see also Block et al. 2015, p. 8). For additional references on this issue, see e.g. Brown (2011), Sinclair (2013), Gernsbacher (2017). Melanie Yergeau's explanation of how nouns and pronouns are relational (they "relate how [we] relate"), changeable, and indeed themselves a "kind of knowing" is also pertinent to this discussion (Yergeau 2018, p. 211-13).
}

Accepted for publication in Transcultural Psychiatry, July 2020 (this is the before-proof version) 
This horse has not been seen properly. It has not been recognised in its horseness, in its particular, concrete, individual, living being; in its needs to-also-roam and play and connect. The trainer has not let the horse be. He has not known his horse properly, and this has impacted the horse's very being.

The example shows something about how interwoven knowing and being are. It shows that the way we know something has consequences for its being, impacts its being.

The example also shows something about the relation between knower and known. Knower and known are linked in their relationship. If the very being of the known can be impacted in the relationship of knowing, then knower and known are tethered to each other, at least for as long as this epistemic relationship holds. This, in turn, also impacts the knower. Because isn't the horse trainer doing his particular kind of knowing badly, if he destroys his horse in his efforts to make money with it? And doesn't this mean that his capacities as knower, that is: his being as this particular knower, as a horse trainer, is impacted by his way of knowing? Knowers act on purpose (McGann 2007). Their intentions, wishes, desires, fears, motivations, and so on-in partdetermine how they know. And their ways of knowing can sometimes defeat their very purposes. They can go against their own motivations and interests.

Knower and known are intertwined. Knowing is an activity-in-relation that impacts both knower and known. Knowing modulates and transforms the being and becoming of both. This makes knowing and being-known tensionful activities, for all involved. This is both a deeply philosophical and a deeply practical issue.

It is also an issue that may not be so easy to understand, especially for those accustomed to a Western, colonising worldview, which considers humans' most sophisticated ways of knowing to be abstract, disconnected, and disinterested. A reader may wonder whether the example is really a good instance of knowing, because the horse trainer has a particular interest when interacting with his horse. What he is doing, one may say, is not knowing; he is, rather, using it. To call what he does knowing, would be to say that his knowing is tainted, biased-and this is not how we are used to thinking of knowing. But the point that Maclaren makes, and I agree with her and will take this idea forward here — a point, moreover, that has been made by other thinkers too 5 is that knowing is precisely like this. That knowing is never, in fact, disinterested. Disinterested knowing is not just an illusion, but even to consider "true" knowing to be abstract and disinterested is unethical, because it merely pretends that knowing has no impact on the known and the knower, and this can lead to harm.

Where knowing in its full ethical significance is taken seriously is in engaged epistemologies. Developmental psychologist Vasu Reddy illustrates this well in her book How Infants Know Minds. Reddy shows how infants, from a much younger age than an individualistic, cognitivist psychology predicts, participate in creating humour, in playing, in being the object of another's attention, in self-recognition (Reddy 2008). Reddy does this work as a psychologist, using anthropological methods like participant observation. This is of course no coincidence, because anthropology and sociology have always been the parts of Western science that have been most closely concerned and aligned with engaged epistemologies and methodologies.

\footnotetext{
${ }^{5}$ E.g. Merleau-Ponty 1945/2012, Heidegger 1959, Levin 1988.
} 
Anthropology, however, has not had a sustained influence on the cognitive sciences, including psychology, even though rapprochements between them have been attempted (Boden 2006). Perhaps it is not so hard to understand why they have not often been comfortable bedfellows. There is something inherently concerned with abstraction, with disconnection, at the heart of the Western, colonial cognitive and medical sciences, which it is hard to break open, let alone dissolve. Western cognitive scientists (including neuroscientists, psychologists, psychiatrists, and many "applied" professions linked with them, such as education, therapy, medicine, social work, care work, and so on), and imperialist society in general, are much maligned by cognitivist, individualist, functionalist assumptions. These assumptions are in fact and in effect divisive. We seem quite convinced that the more abstractly we think and work, the more capable we are. A case in point is the thought that if we could only make autistic people learn the 'rules of social interaction,' they would become socially fluent. But the idea that something like this can work pulls all of human capacity to the side of 'coldly' dealing with abstract rules. It ignores the wealth, depth, and intricacy of the lived, intersubjective sensitivities and powers that ground and pervade our abstract capacities.

From phenomenology to feminism to decolonial theories to critical psychiatry, we know that we can only understand subjectivity and knowing-human intentionality-by looking at interactions between real, toiling, worldly bodies (e.g. Merleau-Ponty 1960, 1945/2012, Lugones 1987, Maclaren 2002, Stawarska 2009a, McNally 2001, Davar 2014, Mills 2014, Dhar 2020, Velez and Tuana 2020). On this kind of understanding, abstract knowing (what colonial cognitive science often takes as the highest form of intelligence) is not so much the lonesome pinnacle of our sophistication, but in fact derives from our essentially dual (not: dualistic!) and connected nature (Stawarska 2009b).

There is an approach to cognitive science that recognises and begins from this. This is the enactive approach. Varela, Thompson and Rosch said, in The Embodied Mind (one of the first "manifestos" of enaction), that

"it is only by having a sense of common ground between cognitive science and human experience that our understanding of cognition can be more complete and reach a satisfying level. We thus propose a constructive task: to enlarge the horizon of cognitive science to include the broader panorama of human, lived experience in a disciplined, transformative analysis" (Varela et al. 1991, p. 14).

That is: to root the view of cognition in lived experience. And moreover, to root it in intersubjective experience (Thompson 2001a,b, De Jaegher and Di Paolo 2007). This means: to see that most of our sense-making is both participatory and situated. How we know is deeply shaped in and by the socio-cultural-historical-materially situated face-to-face interactions we engage in (Lugones 1987, Di Paolo 2015, 2016, Maclaren 2017, 2018, Di Paolo et al. 2018).

But an experiential-intersubjective ground for cognitive science is not something pristine or innocent. As soon as we understand that cognition is social, communal, and interactive, we also understand that it is a mess. This is something that rationalist, individualist, functionalist accounts do not even see, but that, as soon as we recognise the intersubjective ground of knowing, becomes clear and unavoidable. We like to ignore this, because messiness seems too hard to deal 
with, especially for a "neat", abstract science. But in cutting out the mess and making everything abstract, rational, detached-'manageable'_we cut out precisely the heart of what is going on. We cut out the making of meaning.

Here is where Western cognitive science can — and needs to-learn from epistemologies that are comfortable with the mess. Epistemologies, in other words, that have engagement at their roots. They can be found in many indigenous worldviews and in what de Sousa Santos calls 'epistemologies of the South' (de Sousa Santos 2007, 2018, Smith 2012). Engaged epistemologies, generally and each in their own ways, understand how knowing is through-and-through ethical and ontological (Kincheloe 2011, Kimmerer 2013, Simpson 2017, Welch 2019). They know that we do not know anything without modulating its being and our own being. That knowing is consequential and has impact. It comes with responsibilities to what we know, to ourselves, to our worlds, views, and practices. There is a connection between these ways of knowing and critiques of and mobilisations against the Global Health Movement, which intends to globalize the Western biomedical idea of mental health (Kirmayer et al. 2003, Mills 2014, Cooper 2015).

Cognitive science, to fully understand human knowing, needs to engage with engaged epistemologies to learn about the responsibility of knowing. But this cannot be a relationship of taking some elements, assimilating them, and forgetting others. The abstract, functionalist approach of traditional cognitive science is fundamentally at odds with engaged epistemologies. Disconnected and dichotomous thinking is at the basis of functionalism, and cognitive science is riddled by an abyss between mind and body, feeling and reason, subject and object of which the bottom is out of sight. What is needed for cognitive science to understand knowing-as-engaging is to first of all begin to see the common ground underlying experience, intersubjectivity, and sense-making. Cognitive science itself needs to begin recognising this, before it can start to engage with engaged epistemologies. This is because, as Sarah Lucia Hoagland says: "it is not because we are able to be scholars that we are positioned to develop knowledge of marginalized others; it is because of how we are positioned in relation to marginalized others that we are able to be scholars" (2020, p. 48).

The enactive approach, with its basis in both existential phenomenology (e.g. Merleau-Ponty 1945/2012) and dynamical systems theory (Thelen and Smith 1994, Juarrero 1999), can recognise the existence and influence of an abstract separation between mind and body, reason and emotion, and so on, while also seeing both elements arise from the same soil. Because, as a science, it roots itself in the material-energetic processes of life, in lived experience, and in intersubjectivity, it is grounded. It is not abstract, but toils; it continually works at understanding, also at a meta-level, by critically reflecting on its own continual theoretical and empirical development (see Di Paolo et al. 2018). This, I think, is the ground from which enactive cognitive science can begin to engage with engaged epistemologies, and to build an understanding of difference in general-including neurodiversity - that does justice to everyone's experience, while also understanding what cognition is at a general level. The point here is that " $[\mathrm{t}]$ he problems facing us are solved, 'not by giving new information'..., but by us 'going on' with each other in a new way" (Katz and Shotter 1996). 


\section{Engaging epistemology}

The enactive approach to cognition defines cognisers as sense-makers. Sense-makers act and interact out of their various cares and concerns. Things matter to sense-makers. Sense-making (cognition, knowing, understanding) happens in relation to the various identities that people maintain, e.g. as a client, a teacher, technician, baker, student, sister, scientist, and so on. Maintaining these identities gives them perspectives from which they view and interact with the world and with each other. They act on the basis of needs that stem directly from these concerns, which form the ever-changing bases of their different identities. All of this, they do as metabolic, sensorimotor, and intersubjective, societally situated, labouring and working bodies (Di Paolo et al. 2018). We have metabolic needs (hunger, thirst), sensorimotor habits that we maintain or try to break (smoking, dieting), and intersubjective concerns ("will they like me?") and agencies. As particular, concrete and situated bodies, sense-makers have needs and constraints on all these levels that intricately relate to each other.

Underlying living sense-making is a basic tension between self-production and self-distinction (Varela 1979, Maturana and Varela 1980). Living beings continually construct themselves out of the environment, and in doing so, also continually distinguish themselves from the environment. Sense-makers deal with the tension between these opposing tendencies by regulating their couplings with their environment in view of their metabolic, sensorimotor, and intersubjective needs and constraints and what the environment has to offer-what we call agency. In this way, enactive sense-makers are continually individuating themselves and ongoingly becoming in interaction (Di Paolo 2018, 2020, Di Paolo et al. 2018).

Sense-makers engage in social interactions, which are emergent processes between people that generate their own dynamics. These processes can pull people in, or push them out. Social interaction processes can self-organise and take on a certain autonomy (De Jaegher and Di Paolo 2007, De Jaegher et al. 2010). The processes that make up social interactions, e.g. the rhythmic dynamics between interactors' breathing and heart-beats, or how their vocabularies align over time, can coordinate in such a way that these processes themselves work to maintain the interaction. As such, interaction processes can-in part-determine how people participate in them. We not only influence each other in our interactions (our intentions, motivations, perspectives are impacted by each other's presence, moves, and utterances), but these interactions themselves, as emergent, coordinating processes, also determine what happens in an encounter. Think of greeting someone you have not seen in a while. Imagine you are used to meeting in a formal context (say, as doctor and patient), but this evening, you bump into each other at a house party. You're feeling jovial and light-hearted. How will you greet each other now? Will you shake hands? Hug? How the greeting in this different situation turns out not only depends on each of your intentions and the context, but is also coordinated there-and-then. Whether it will end up being a hug or a handshake (or a clumsy 'neither') emerges, in part, out of the interaction itself. Each of you participate in it, each of you bring expectations. There is a certain pre-coordination, but the greeting that emerges tonight is co-determined by the interactive normativity (by the coordination dynamics that emerge between you in context), and what each of you brings.

Enaction searches for the principles of sense-making by asking What is at stake for a sensemaker?, thereby doing justice to their specific bodily needs, self-organisation, constraints, context, and capabilities. Asking what is at stake for someone helps to see what identities they are 
maintaining, what their concerns are in the situation, and thereby why they behave in certain ways.

The enactive approach also theorises language, elaborating on Bakhtin's idea that language is a living stream in which we participate (Bakhtin 1981, 1986, Cuffari et al. 2015, Di Paolo et al. 2018). It is a living stream of utterances, all around us, that we take up, agree with or contest, struggle with, do and do not understand, carry forward, copy, repeat, address to others and are addressed by, modulate, transform. This stream of utterances moves through us and changes us. We variously pick it up and play with it. As we participate in language (which, as linguistic bodies_as humans_-we continually do), both we and language change. Our organisation as living, sensorimotor, and intersubjective bodies is modified by language as we participate in it. Language can affect us, down to the metabolic level. Think of how a harsh word from a loved one can make it hard to digest dinner (cf. research showing that quality of marital relationship impacts wound-healing, Kiecolt-Glaser et al. 2005).

We incorporate other persons' and socio-cultural ways of speaking, of thinking, of judging. We can even incarnate others' agencies. This means that others can 'speak through us'. When this happens, we don't know whether it is us speaking, or the other person. You may have your grandmother's “clean your plate!" in your ears after dinner. You have incarnated your grandmother. She is a small part of how you organise your life, the actions you take. Is it you or her speaking? In this case, you may be fine with this particular incarnation, but other such 'voices' you may not want to accept, you fight with. This is the tension of self-production and selfdistinction that linguistic bodies deal with: maintaining your ways of speaking, thinking, interpreting, acting, meaning, presenting and being yourself, while always participating in (including rejecting, questioning, critiquing, etc.) the living stream of language that you move in, incorporating and incarnating others' agencies.

This enactive way of approaching (human) sense-making is, then, an engaged or even an engaging epistemology (De Jaegher 2019). What does this mean? Maclaren (2002), remember, said that knowing is letting be. It is a balancing between the ongoing becomings of both known and knower. The knower has to let the known be, in order to know it. Letting be is an activity, but an activity of at the same time approaching (determining) the known, and letting it be-itself. Too much interference with the known, and it will be over-determined-in danger of losing itself-so that we do not truly know it, or misunderstand it at best. Too little interference, to the point of disengaging from it, will mean we also do not know it, because we are not in touch with it anymore (we under-determine it). Knowing as letting be is a careful epistemological balancing act that happens only in a relation.

This idea of knowing as letting be is unusual, and perhaps a little difficult to understand. But there is an area in our lives where we know these tensions of letting be well. We know thesometimes difficult-balancing act of letting be in our loving relationships. I'm thinking here in particular of the most basic tension in loving relationships: that between being in relation and being yourself. How much do you give in, how much do you assert yourself, and still remain wellconnected? We know this kind of tension from parent-child relations, friendships, romantic and sexual relationships (see e.g. Gilligan 1982, 2003). What furthermore characterises every loving relationship at its most basic level, is that it is existential. Loving goes out from the core of your being - it involves you existentially_and goes out to a particular other, whom your loving 
reaches out to, because of their being. It is thus a radically existential relationship. Loving is a nonneutral, particular, concrete involvement, with particular, concrete others, in particular, concrete interactions. In this kind of relationship, not only you, but the other, as well as the interactions between you, impact all of it. This relationship, then, has three elements: the ones who love (that's two), and their relationship itself. Each of these plays a fundamental part in loving. Leave one out, and there is no loving. (The elements are necessary and sufficient.) This is an extension and deepening of the primordial idea of participatory sense-making. Here also, the individual participants co-determine and are co-determined by their interactions (De Jaegher and Di Paolo 2007, De Jaegher et al. 2010). In loving, this interaction involves you basically and existentially. Loving is an existential dialectic that swirls up both its individuals and its relational/interactional elements into an ongoing storm.

The problems of the colonial tendency to think epistemology dichotomously stem from forgetting this root and core of what knowing is. Knowing is like loving in the sense that both are manifestations of the same existential way of relating (De Jaegher 2019). Loving and knowing are both fundamental ways of relating in which the lover (the knower) is existentially involved with a particular other, and in which their relation, as well as each of them as participants, play basic primary roles, and can all influence and impact on each other. Already on the enactive idea that living beings are metabolically involved in their sense-making, what knowing is is deeply determined by what is existentially necessary for the organism. As living beings, we are tied to our life provisioning - our processes of living are completely intertwined with our environments.

An engaged epistemology, one that understands the depths and widths of human knowing by engaging with people, can thus be understood as a loving and knowing epistemology, or an engaging epistemology.

Defining loving as I do (in this conceptual-experiential exercise) ${ }^{6}$, begins from the most basic, minimal form of both loving and knowing. The form of knowing that is analogous to loving, that is, the most basic form of knowing, is this form of relating. Maclaren (2002) makes the same point. She also says that the fact that the horse trainer could get it so wrong with his horse, destroying it in the process (and also damaging himself as a trainer), shows that letting be is something we have to learn. Moreover, she argues, we learn it from letting others be. Letting be, she says, is first of all intersubjective, in-relation-with-others. I agree with this. Her example shows that knower and known are existentially engaged. Both of their being is implicated in this relation between them. More even: Maclaren also says (2018) that we are ontologically intimate with each other, which means that in knowing each other and interacting with each other, we cannot help but transgress each other. This is perhaps the strongest explication of why epistemology is ethical.

What can this enactive, engaging epistemology do to help better see how autistic people participate, to let autistic people be (themselves), and to improve interactions between autistic and non-autistic people?

\footnotetext{
${ }^{6}$ Note that the definition of loving I use here is fundamental and minimal. It is in this form that knowing is similar to (if not just the same as) loving. I am not talking about more complex forms of loving, like unrequieted love. The exercise I'm doing here is experiential-conceptual: I point to a similiarty in ways of relating, in order to elucidate knowing. A further comparison of the differences and similarities between loving and knowing in more intricate (I would say, derived) forms and relations, which in a sense come after this shared core, is needed, and may itself be able to further elucidate the troubles of both loving and knowing, but this is work for future research (see also De Jaegher 2019).
} 


\section{Implications for transcultural psychiatry: heeding what participation teaches us}

What guidelines for both seeing and improving participation can we derive from the enactive approach sketched in the previous sections? The first recommendation is to start from where and how people are, and to let them be where and how they are. To begin any engagement from there. Some autism research already takes this as a starting point. It begins to shed light on some of the sophistication with which autistic people participate in social interactions.

Adopting the attitude of letting be does not close the door to scientific research, or to therapy. On the contrary, this attitude can inform and help generate scientific hypotheses and improve practices. In our book Linguistic Bodies, we put forward two enactive hypotheses about autistic linguistic participation. First, we propose that autistic people tend to over- and under-regulate interaction dynamics. And second, we propose they braid utterances differently. This means that autistic people tend to engage with different threads of meaning than non-autistics do (Di Paolo et al. 2018, chapter 10). This may make it hard for them to pick up on certain meanings. Autism is diverse, it manifests in diverse ways, and autistic people interact in many ways. The maxim we worked out in Linguistic Bodies is that, in the face of all this diversity, one thing to do is to enhance participation, if and when desired. Also if this means to take breaks, to retreat, to remain sometimes unseen, to not know, and to attend to "a rhetoric that tics, a rhetoric that shrieks and wails and sometimes bites" (Yergeau 2015, p. 93). A participation between non-autistic and autistic people that lets each one be and become.

Several studies show that this works well, in both autistic children and adults. For instance, discourse analysis shows that, with sensitive interaction partners, autistic children can play with pedagogical instructions, with withdrawal and engagement, with language, with self-presentation and -interpretation, and with forming their identity (Ochs et al. 2004; Bottema-Beutel and Smith 2013, Sterponi and Fasulo 2010, Sterponi and Shankey 2014, Bottema-Beutel 2017). They can also collaborate and have awareness of others when given technology designed to support their ways of interacting (Holt and Yuill 2014; 2017). Ethnographic research shows how autistic children become both more stable and more flexible in their bodily participation when therapists use sensory integration techniques and take them on narrative journeys (Park 2008, 2010, 2012, see also Lee et al. 2016). In these investigations, the autistic children, their interaction partners, and the researchers are able to let the child be, while also staying with their own motivations, aims, and perspectives in the interaction. In this way, they can balance the tensions in participation over time, including moving through breakdowns.

Participatory design researchers explicitly involve autistic people as co-investigators to develop technologies to enhance their quality of life. Together, they engage in iterative co-design processes to explore and reflect on what would be most helpful. Approaches like this stimulate rethinking ideas of empowerment, outcomes, and assistive technology (e.g. van Dijk et al. 2019, Frauenberger et al. 2019, see also Parsons et al. 2017, Fletcher-Watson et al. 2018, Parsons et al. 2020). Such approaches unearth the micro-ethics of this kind of practice, and naturally go together with critical reflections on empathy, which-if understood as inferring another's intentions_-risks being one-directional and thereby over-determining people's needs (Spiel et al. 2017, 2019, 2020). 
Most autistic people desire friendship, intimacy, and social relations. They may not always know so well how to have them, or may simply have them in different ways than non-autistics do (Daniel and Billingsley 2010, Calder et al. 2013, Vine Foggo and Webster 2017, Sedgewick and Pellicano 2019, Sedgewick et al. 2019, Cresswell et al. 2019). Many experience loneliness, but "talking together" about it can be a "potent remedy", as Williams shows in a sensitive study that integrates community building and critical reflections on participation research (Williams 2020). Crompton and colleagues (2020) show that having and maintaining friendships is easier with other autistic people than with non-autistics, for all the reasons one may expect: with other autistics, people feel like they belong, that they can be themselves and are understood. In interactions with non-autistics, in contrast, autistics more often feel misunderstood, feel the stresses of being a minority, and cannot so easily be themselves.

These are all examples and considerations of seeing and inviting autistic participation. To do so means to do justice to participatory sense-making's three elements: each participant's sensemaking, needs and constraints — what matters to them-and the emergent dynamics of the interactions between them. Research shows that autistic interactions have particular characteristics and dynamics (De Jaegher 2013, Bolis et al. 2017, Heasman and Gillespie 2019, Crompton, Ropar, et al. 2020). Understanding these better can help combat misperceptions that come from taking a merely neurotypical perspective, and can improve interactions between autistic and non-autistic people (see also Sinclair 2010).

To conclude, I'd like to come back to where we began this paper. Milton hopes that "those wanting to research the sociality of autistic people may take up the challenge of an imitation game" (Milton 2014, p. 801). I would not. What I would rather do is to continue interacting with autistic people in ways that are both serious and playful, open and vulnerable, each of us starting from our own points of view and expertise, open to who we are encountering, and to changing and transforming in and through these interactions (and researching and building methodologies on this basis, e.g. De Jaegher et al. 2017). I wholeheartedly agree with Milton and others that the field of autism research needs full "ethical and epistemological integrity" (ibid., p. 796), and that this requires that autistic people participate at all levels of research. But much more is to be gained from engagement than from either fishbowling or imitation games. The road to a solution lies in sensitively moving into and out of what emerges between us. The enactive approach in cognitive science supports and grounds doing this.

This, then, I think, is one way to respond to the questions Melanie Yergeau asks: "What to do with scholarship that denies autistic agency, denies autistic voice, denies autistic personhood?" and "how can we create more inclusive spaces to speak back to these theories of lack?" (Yergeau 2015, p. 89-90). I would say: by understanding how everyone can participate in interactions, and understanding what concretely matters to people in each situation. It is up to all of us to be inclusive. We can do this by continually developing the scientific understanding of participatory sense-making, and by learning to trust its processes in practice.

Reading decolonial, indigenous, and autistic thinkers and educators, what I hear-even if it is often not said so explicitly_-is a plea for Western scientists to be silent for a change. To participate in silence. This may help us listen. In Audre Lorde's words, it may help us recognise that 
"[w]ithin the interdependence of mutual (nondominant) differences lies that security which enables us to descend into the chaos of knowledge and return with true visions of our future, along with the concomitant power to effect those changes which can bring that future into being. Difference is that raw and powerful connection from which our personal power is forged" (Lorde 2017, p. 91).

An engaged epistemology does not mean that we will-or have to-know each other exhaustively. It does mean that knowing each other will never be finished, because each of us keep on developing, both apart and in relation to each other. That is why this is not just an engaged, but an engaging epistemology. It engages us.

It is true, especially regarding questions like the one addressed in this paper, that epistemological integrity needs ethical integrity. It also needs an appropriate ontology, and this ontology is one of ongoing becoming-in-relation. This is bound to involve deep tensions, which we can move through and survive, or not. Understanding that loving and knowing will always involve such tensions should help with moving through them and, in the process, being able to truly recognise each other, even if fleetingly (because the possibility is always there to be recognised wrongly, but also to be recognised better, recognised again).

What bringing together insights from indigenous epistemologies, enactive cognitive science, and the neurodiversity movement does, is to deepen the insight at the heart of participatory sense-making, which is that engaging with each other means to stand on one's own ground and, from there, to engage in social interactions, which will entail breakdowns, repairs, and transformations, of oneself and of the relationship. This is engaging knowing.

As for the field of transcultural psychiatry, both the clinical and the research practice can learn from explicitly recognising these tensions inherent in engagement. When Melissa Park says, "the work to cultivate experiences that matter to individuals remains an 'underground practice' ... that continues to create ongoing dilemmas deeply felt in clinical practice" (Park 2012, S34), I wonder what would happen if we brought these tensions to the surface? As Park (2008, 2010, 2012) and other researchers show, we may be able to deal with them better than we thought. That is what engagement-sensitive methods can bring to clinical work and to the sciences of the mind: a lived understanding of our human (in)abilities to participate, and that we can trust them (however paradoxical this may seem at times). 


\section{Acknowledgements}

Thank you Jo Bervoets, Luc De Jaegher and Mieke Koppers, Ezequiel Di Paolo, and participants of the 2019 Advanced Study Institute in Cultural Psychiatry Cultural Poetics of Illness and Healing: Embodiment, Enactment and the Politics of Experience, June 26-28, Division of Social \& Transcultural Psychiatry, McGill University, Montreal (CA), especially Keven Lee, Melissa Park, and Laurence Kirmayer. A deep thank you also to the three anonymous reviewers, one of whom in particular strongly pulled on me to bring some of the ideas in this paper significantly forward. And finally, thank you to the participants of the \#AutismDialogues at Dialogica UK for helping me understand yet better the ideas being developed here.

\section{Funding information}

This work was financially supported by a Ramón y Cajal Fellowship to the author (RYC-201314583) and by the Inter-Identidad project (FFI2014-52173-P), both funded by the Spanish Ministry of Science, Innovation and Universities; and by a Basque Government Group Call funding (IT1228-19).

\section{Author biography}

Hanne De Jaegher, PhD, is Senior Researcher in the Department of Philosophy, University of the Basque Country, Spain, and Visiting Research Fellow in the Department of Psychology, University of Sussex, UK. She is also co-Director of Dialogica UK. As a philosopher and cognitive scientist, she studies how we think, work, play-basically, live and love-together. For this, she developed the enactive theory of intersubjectivity called participatory sense-making, a comprehensive framework for investigating our social lives. The concepts and methods of participatory sense-making build bridges between different disciplines, and find application in real-life issues such as autism, therapy, education, and the arts. In turn, these applications inform the further construction of the theory.

\section{$\underline{\text { References }}$}

Bakhtin, M. M. (1981). The Dialogic Imagination. Four Essays by M.M. Bakbtin. Austin: University of Texas Press.

Bakhtin, M. M. (1986). Speech Genres and Other Late Essays (V. W. McGee, Trans.). Austin, TX: University of Texas Press.

Baron-Cohen, S., Tager-Flusberg, H., \& Lombardo, M. (2013). Understanding Other Minds: Perspectives From Developmental Social Neuroscience. Oxford: Oxford University Press.

Benjamin, J. (1988). The Bonds of Love. Psychoanalysis, Feminism and the Problem of Domination New York: Pantheon Press.

Block, P., Kasnitz, D., Nishida, A., \& Pollard, N. (2015). Occupying Disability: Critical Approaches to Community, Justice, and Decolonizing Disability. New York: Springer.

Boden, M. (2006). Mind as Machine: A History of Cognitive Science. Oxford: Oxford University Press. 
Bolis, D., Balsters, J., Wenderoth, N., Becchio, C., \& Schilbach, L. (2017). Beyond autism: introducing the dialectical misattunement hypothesis and a bayesian account of intersubjectivity. Psychopathology, 50(6), 355-372. doi:10.1159/000484353

Bottema-Beutel, K. (2017). Glimpses into the Blind Spot: Social Interaction and Autism. Journal of Communication Disorders, 68, 24-34. doi:https://doi.org/10.1016/j.jcomdis.2017.06.008

Bottema-Beutel, K., \& Smith, N. (2013). The interactional construction of identity: An adolescent with autism in interaction with peers. Linguistics and Education, 24(2), 197-214. doi:http://dx.doi.org/10.1016/j.linged.2012.12.002

Brown, L. (2011). The Significance of Semantics: Person-First Language: Why It Matters Retrieved from https://www.autistichoya.com/2011/08/significance-of-semantics-personfirst.html, 16/09/2019

Calder, L., Hill, V., \& Pellicano, E. (2013). 'Sometimes I want to play by myself: Understanding what friendship means to children with autism in mainstream primary schools. Autism, 17(3), 296-316. doi:10.1177/1362361312467866

Caldwell, P. (2006). Speaking the other's language: Imitation as a gateway to relationship. Infant and Child Development, 15(3), 275-282.

Collins, H. M., \& Evans, R. (2007). Rethinking Expertise. Chicago: The University of Chicago Press.

Cooper, S. (2015). Prising open the 'black box': An epistemological critique of discursive constructions of scaling up the provision of mental health care in Africa. Health, 19(5), 523-541. doi:10.1177/1363459314556905

Coulthard, G. (2014). Red Skin, White Masks. Rejecting the Colonial Politics of Recognition. Minneapolis: University of Minnesota Press.

Cresswell, L., Hinch, R., \& Cage, E. (2019). The experiences of peer relationships amongst autistic adolescents: A systematic review of the qualitative evidence. Research in Autism Spectrum Disorders, 61, 45-60. doi:https://doi.org/10.1016/j.rasd.2019.01.003

Crompton, C. J., Ropar, D., Evans-Williams, C. V., Flynn, E. G., \& Fletcher-Watson, S. (2020). Autistic peer-to-peer information transfer is highly effective. Autism, $O(0)$. doi:10.1177/1362361320919286

Crompton, C. J., Hallett, S., Ropar, D., Flynn, E., \& Fletcher-Watson, S. (2020). 'I never realised everybody felt as happy as I do when I am around autistic people': A thematic analysis of autistic adults' relationships with autistic and neurotypical friends and family. Autism, $O(0)$, 1362361320908976. doi:10.1177/1362361320908976

Cuffari, E., Di Paolo, E., \& De Jaegher, H. (2015). From participatory sense-making to language: There and back again. Phenomenology and the Cognitive Sciences, 14(4), 1089-1125. doi:10.1007/s11097-014-9404-9

Daniel, L. S., \& Billingsley, B. S. (2010). What boys with an autism spectrum disorder say about establishing and maintaining friendships. Focus on Autism and Other Developmental Disabilities, 25(4), 220-229. doi:10.1177/1088357610378290

Davar, B. V. (2014). Globalizing psychiatry and the case of 'vanishing' alternatives in a neocolonial state. Disability and the Global South, 1(2), 266-284.

Davidson, J., \& Orsini, M. (Eds.). (2013). Worlds of Autism: Across the Spectrum of Neurological Difference. Minneapolis: University of Minnesota Press. 
De Jaegher, H. (2013). Embodiment and sense-making in autism. Frontiers in Integrative Neuroscience, 7, 15. doi:10.3389/fnint.2013.00015

De Jaegher, H. (2019). Loving and knowing. Reflections for an engaged epistemology. Phenomenology and the Cognitive Sciences. doi:10.1007/s11097-019-09634-5

De Jaegher, H., \& Di Paolo, E. (2007). Participatory Sense-Making: An enactive approach to social cognition. Phenomenology and the Cognitive Sciences, 6(4), 485-507. doi:10.1007/s11097-0079076-9

De Jaegher, H., Di Paolo, E. A., \& Gallagher, S. (2010). Can social interaction constitute social cognition? Trends in Cognitive Sciences, 14(10), 441-447. doi:10.1016/j.tics.2010.06.009

De Jaegher, H., Pieper, B., Clénin, D., \& Fuchs, T. (2017). Grasping intersubjectivity: an invitation to embody social interaction research. Phenomenology and the Cognitive Sciences, 16(3), 491523. doi:10.1007/s11097-016-9469-8

de Sousa Santos, B. (2007). Another knowledge is possible: Beyond northern epistemologies. London: Verso.

de Sousa Santos, B. (2018). The End of the Cognitive Empire: The Coming of Age of Epistemologies of the South. Durham: Duke University Press.

Dhar, A. (2020). Madness and Subjectivity: A Cross-Cultural Examination of Psychosis in the West and India. Abingdon: Routledge.

Di Paolo, E. A. (2015). Interactive time-travel: On the intersubjective retro-modulation of intentions. Journal of Consciousness Studies, 22(1-2), 49-74.

Di Paolo, E. (2016). Participatory Object Perception. Journal of Consciousness Studies, 23(5-6), 228-258.

Di Paolo, E. A. (2018). The enactive conception of life. In A. Newen, L. de Bruin, \& S. Gallagher (Eds.), The Oxford Handbook of Cognition: Embodied, Embedded, Enactive, and Extended (pp. 71-94). Oxford: Oxford University Press.

Di Paolo, E. A. (2020). Enactive becoming. Phenomenology and the Cognitive Sciences. doi:10.1007/s11097-019-09654-1

Di Paolo, E. A., \& De Jaegher, H. (2012). The Interactive Brain Hypothesis. Frontiers in Human Neuroscience, 6(163). doi:10.3389/fnhum.2012.00163

Di Paolo, E. A., Cuffari, E. C., \& De Jaegher, H. (2018). Linguistic Bodies. The Continuity Between Life and Language. Cambridge, MA: MIT Press.

Fletcher-Watson, S., De Jaegher, H., van Dijk, J., Frauenberger, C., Magnée, M., \& Ye, J. (2018). Diversity computing. ACM Interactions, 25(5), 28-33.

Fletcher-Watson, S., Adams, J., Brook, K., Charman, T., Crane, L., Cusack, J., Leekam, S., Milton, D., Parr, J., Pellicano, E. (2019). Making the future together: Shaping autism research through meaningful participation. Autism, 23(4), 943-953 doi:10.1177/1362361318786721

Fletcher-Watson, S., \& Crompton, C. J. (2019). Autistic people may lack social motivation, without being any less human. Behavioral and Brain Sciences, 42.

Frauenberger, C., Spiel, K., \& Makhaeva, J. (2019). Thinking OutsideTheBox - Designing Smart Things with Autistic Children. International Journal of Human-Computer Interaction, 35(8), 666678. doi:10.1080/10447318.2018.1550177

Galbusera, L., Finn, M. T., Tschacher, W., \& Kyselo, M. (2019). Interpersonal synchrony feels good but impedes self-regulation of affect. Scientific Reports, 9(1), 1-12. 
Gernsbacher, M. A. (2006). Toward a behavior of reciprocity. Journal of Developmental Processes, 1(138-152).

Gernsbacher, M. A. (2017). Editorial Perspective: The use of person-first language in scholarly writing may accentuate stigma. Journal of Child Psychology and Psychiatry and Allied Disciplines, 58(7), 859-861. doi:https://doi.org/10.1111/jcpp.12706

Gilligan, C. (1982). In a Different Voice. Cambridge, MA: Harvard University Press.

Gilligan, C. (2003). The Birth of Pleasure: A New Map of Love. New York: Vintage books.

Heasman, B., \& Gillespie, A. (2019). Neurodivergent intersubjectivity: Distinctive features of how autistic people create shared understanding. Autism, 23(4), 910-921. doi:10.1177/1362361318785172

Heidegger, M. (1959). Gelassenheit. Pfullingen: Neske.

Hens, K. (2019). The many meanings of autism: conceptual and ethical reflections. Developmental Medicine \& Child Neurology, 61(9), 1025-1029. doi:10.1111/dmcn.14278

Hoagland, S. L. (2020). Aspects of the coloniality of knowledge. Critical Philosophy of Race, 8(12), 48-60. doi:10.5325/critphilrace.8.1-2.0048

Holt, S., \& Yuill, N. (2014). Facilitating other-awareness in low-functioning children with autism and typically-developing preschoolers using dual-control technology. Journal of Autism and Developmental Disorders, 44, 236-248.

Holt, S., \& Yuill, N. (2017). Tablets for two: how dual tablets can facilitate other-awareness and communication in learning disabled children with autism. International Journal of Child-Computer Interaction, 11, 72-82.

Jaswal, V. K., \& Akhtar, N. (2019). Being versus appearing socially uninterested: Challenging assumptions about social motivation in autism. Behavioral and Brain Sciences, 42, e82. doi:10.1017/S0140525X18001826

Juarrero, A. (1999). Dynamics in Action. Cambridge, MA: MIT Press.

Kapp, S. K. (Ed.) (2020). Autistic Community and the Neurodiversity Movement. Stories from the Frontline: Palgrave Macmillan.

Katz, A. M., \& Shotter, J. (1996). Hearing the patient's 'voice': Toward a social poetics in diagnostic interviews. Social Science \& Medicine, 43(6), 919-931.

Kenny, L., Hattersley, C., Molins, B., Buckley, C., Povey, C., \& Pellicano, E. (2016). Which terms should be used to describe autism? Perspectives from the UK autism community. Autism, 20(4), 442-462. doi:10.1177/1362361315588200

Kiecolt-Glaser, J. K., Loving, T. J., Stowell, J. R., Malarkey, W. B., Lemeshow, S., Dickinson, S. L., \& Glaser, R. (2005). Hostile marital interactions, proinflammatory cytokine production, and wound healing. Archives of General Psychiatry, 62(12), 1377-1384.

Kimmerer, R. W. (2013). Braiding Sweetgrass: Indigenous Wisdom, Scientific Knowledge and the Teachings of Plants. Minneapolis: Milkweed Editions.

Kincheloe, J. (2011). Critical ontology and Indigenous ways of being. In k. hayes, S. R. Steinberg, \& K. Tobin (Eds.), Key Works in Critical Pedagogy. Rotterdam: Sense Publishers.

Kirmayer, L., Simpson, C., \& Cargo, M. (2003). Healing Traditions: Culture, Community and Mental Health Promotion with Canadian Aboriginal Peoples. Australasian Psychiatry, 11(1_suppl), S15-S23. doi:10.1046/j.1038-5282.2003.02010.x 
Koenig, K., De Los Reyes, A., Cicchetti, D., Scahill, L., \& Klin, A. (2009). Group Intervention to Promote Social Skills in School-age Children with Pervasive Developmental Disorders: Reconsidering Efficacy. Journal of Autism and Developmental Disorders, 39(8), 1163-1172. doi:10.1007/s10803-009-0728-1

Kyselo, M. (2014). The body social: An enactive approach to the self. Frontiers in Psychology, 5. doi:10.3389/fpsyg.2014.00986

Lee, K., Lambert, H., Wittich, W., Kehayia, E., \& Park, M. (2016). The use of movementbased interventions with children diagnosed with autism for psychosocial outcomes-A scoping review. Research in Autism Spectrum Disorders, 24, 52-67. doi:http://dx.doi.org/10.1016/j.rasd.2015.12.011

Levin, D. M. (1988). The Opening of Vision: Nibilism and the Postmodern Situation. London: Routledge.

LeVine, R. A., Dixon, S., LeVine, S., Richman, A., Leiderman, P. H., Keefer, C. H., \& Brazelton, T. B. (1994). Child care and culture: Lessons from Africa. Cambridge: Cambridge University Press.

Lorde, A. (2017). Your Silence Will Not Protect You. With a preface by Reni Eddo-Lodge and an introduction by Sara Abmed. London: Silver Press.

Lugones, M. (1987). Playfulness, "world"-travelling, and loving perception. Hypatia, 2(2), 319.

Lymer, J. (2011). Merleau-Ponty and the affective maternal-foetal relation. Parrhesia(13), 126143.

Maclaren, K. (2002). Intercorporeality, Intersubjectivity and the Problem of 'Letting Others Be'. Chiasmi International, 4, 187-210.

Maclaren, K. (2017). Merleau-Ponty on human development and the retrospective realization of potential. Phenomenology and the Cognitive Sciences, 16(4), 609-621. doi:10.1007/s11097-017-9519$\mathrm{x}$

Maclaren, K. (2018). Intimacy as transgression and the problem of freedom. Journal of Critical Phenomenology, 1(1), 18-40.

Maddox, B. B., Crabbe, S., Beidas, R. S., Brookman-Frazee, L., Cannuscio, C. C., Miller, J. S., ... Mandell, D. S. (2019). "I wouldn't know where to start": Perspectives from clinicians, agency leaders, and autistic adults on improving community mental health services for autistic adults. Autism, doi:10.1177/1362361319882227

Maturana, H. R., \& Varela, F. J. (1980). Autopoiesis and Cognition. The Realization of the Living. Dordrecht: Reidel.

McGann, M. (2007). Enactive theorists do it on purpose. Phenomenology and the Cognitive Sciences, 6(4), 463-483.

McNally, D. (2001). Bodies of Meaning. New York: SUNY Press.

Meek, E. L. (2011). Loving to Know. Introducing Covenant Epistemology. Eugene, Oregon: Cascade Books.

Mejía-Arauz, R., Rogoff, B., Dayton, A., \& Henne-Ochoa, R. (2018). Collaboration or negotiation: two ways of interacting suggest how shared thinking develops. Current Opinion in Psychology, 23, 117-123. doi:https://doi.org/10.1016/j.copsyc.2018.02.017 
Merleau-Ponty, M. (1945/2012). Phenomenology of Perception (D. A. Landes, Trans.). London: Routledge.

Merleau-Ponty, M. (1960). The child's relations with others (W. Cobb, Trans.). In M. MerleauPonty (Ed.), The Primacy of Perception. Evanston: Northwestern University Press.

Milton, D. E. M. (2012). On the ontological status of autism: the 'double empathy problem'. Disability \& Society, 27(6), 883-887. doi:10.1080/09687599.2012.710008

Milton, D. E. (2014). Autistic expertise: a critical reflection on the production of knowledge in autism studies. Autism, 18(7), 794-802.

Milton, D. E., \& Moon, L. (2012). The normalisation agenda and the psycho-emotional disablement of autistic people. Autonomy, the Critical Journal of Interdisciplinary Autism Studies, 1(1).

Milton, D., Murray, D., Martin, N., Ridout, S., \& Mills, R. (Eds.). (2020). Neurodiversity Reader. Shoreham-by-Sea: Pavilion Publishing.

Mills, C. (2014). Decolonizing Global Mental Health: The Psychiatrization of the Majority World. Abingdon: Routledge.

Nicolaidis, C., Raymaker, D., Kapp, S. K., Baggs, A., Ashkenazy, E., McDonald, K., .. Joyce, A. (2019). The AASPIRE practice-based guidelines for the inclusion of autistic adults in research as co-researchers and study participants. Autism, 23(8), 2007-2019.

Nind, M., \& Hewitt, D. (1994). Access to Communication. London: David Fulton.

Nind, M., \& Powell, S. (2000). Intensive Interaction and autism: Some theoretical concerns. Children \& Society, 14, 98-109.

Ochs, E., Kremer-Sadlik, T., Sirota, K. G., \& Solomon, O. (2004). Autism and the Social World: An Anthropological Perspective. Discourse Studies, 6(2), 147-183. doi:10.1177/1461445604041766

Ozonoff, S., \& Miller, J. N. (1995). Teaching theory of mind: A new approach to social skills training for individuals with autism. Journal of Autism and Developmental Disorders, 25, 415-433.

Park, M. (2008). Making scenes: imaginative practices of a child with autism in a sensory integration-based therapy session. Medical Anthropology Quarterly, 22, 234-256.

Park, M. (2010). Beyond calculus: Apple-apple-apple-ike and other embodied pleasures for a child diagnosed with autism in a sensory integration based clinic. Disability Studies Quarterly, 30(1).

Park, M. (2012). Pleasure, Throwing Breaches, and Embodied Metaphors: Tracing Transformations-in-Participation for a Child With Autism to a Sensory Integration-Based Therapy Session. OTJR : occupation, participation and health, 32, S34-47. doi:10.3928/1539449220110906-05

Parsons, S., Yuill, N., Brosnan, M., \& Good, J. (2017). 'A child with autism only has one childhood': main themes and questions for research from the 'Digital Bubbles' seminar series. Journal of Enabling Technologies, 11(3), 113-119.

Parsons, S., Yuill, N., Good, J., \& Brosnan, M. (2020). 'Whose agenda? Who knows best? Whose voice?' Co-creating a technology research roadmap with autism stakeholders. Disability \& Society, 35(2), 201-234. doi:10.1080/09687599.2019.1624152

Pellicano, E. (2020). Broadening the research remit of participatory methods in autism science - a commentary on Happé and Frith (2020). Journal of Child Psychology and Psychiatry, 61(3), 233235. doi:10.1111/jcpp.13212 
Pellicano, E., Crane, L., Gaudion, K., \& Shaping Autism Research Team (2017). Participatory autism research: $A$ starter pack. London, UK: UCL Institute of Education.

Reddy, V. (2008). How Infants Know Minds. Cambridge, MA: Harvard University Press.

Reddy, V. (2012). Moving others matters. In A. Foolen, U. Lüdtke, T. P. Racine, \& J. Zlatev (Eds.), Moving Ourselves, Moving Others: Motion and Emotion in Intersubjecitivity, Consciousness, and Language. Amsterdam: John Benjamins.

Schaber, A. (Producer). (2014, 12 June 2017). Ask an Autistic \#21 - What About Eye Contact? Ask An Autistic. [Youtube Video] Retrieved from https://www.youtube.com/watch?v=QXM9Mj5Zd7I

Sedgewick, F., \& Pellicano, E. (2019). Friendships on the autism spectrum. In B. Carpenter, F. Happé, \& J. Egerton (Eds.), Girls and Autism: Educational, Family and Personal Perspectives. London: Routledge.

Sedgewick, F., Crane, L., Hill, V., \& Pellicano, E. (2019). Friends and lovers: The relationships of autistic and neurotypical women. Autism in Adulthood, 1(2), 112-123. doi:10.1089/aut.2018.0028

Simpson, L. B. (2017). As We Have Always Done. Indigenous Freedom Through Radical Resistance. Minneapolis: University of Minnesota Press.

Sinclair, J. (2010). Being autistic together. Disability Studies Quarterly, 30(10).

Sinclair, J. (2013). Why I dislike "Person First" language. Autonomy, the Critical Journal of Interdisciplinary Autism Studies, 1(2), 2-3.

Singer, J. (1999). Why can't you be normal for once in your life? In M. Corker \& S. French (Eds.), Disability Discourse: Open University Press.

Smith, L. T. (1999). Decolonizing Methodologies: Research and Indigenous Peoples (2nd ed. 2012). London: Zed Books.

Spiel, K., Brulé, E., Frauenberger, C., Bailley, G., \& Fitzpatrick, G. (2020). In the details: the micro-ethics of negotiations and in-situ judgements in participatory design with marginalised children. CoDesign, 16(1), 45-65. doi:10.1080/15710882.2020.1722174

Spiel, K., Frauenberger, C., \& Fitzpatrick, G. (2017). Experiences of autistic children with technologies. International Journal of Child-Computer Interaction, 11, 50-61. doi:https://doi.org/10.1016/j.ijcci.2016.10.007

Spiel, K., Frauenberger, C., Keyes, O., \& Fitzpatrick, G. (2019). Agency of Autistic Children in Technology Research-A Critical Literature Review. ACM Trans. Comput.-Hum. Interact., 26(6), 1-40. doi:10.1145/3344919

Stawarska, B. (2009a). Dialogue at the limit of phenomenology. Chiasmi International, 11, 145156.

Stawarska, B. (2009b). Between You and I. Dialogical Phenomenology. Athens, Ohio: Ohio University Press.

Sterponi, L., \& Fasulo, A. (2010). "How to go on": Intersubjectivity and progressivity in the communication of a child with autism. ETHOS, 38(1), 116-142.

Sterponi, L., \& Shankey, J. (2014). Rethinking echolalia: repetition as interactional resource in the communication of a child with autism. Journal of Child Language, 41(2), 275-304.

Thelen, E., \& Smith, L. B. (1994). A Dynamic Systems Approach to the Development of Cognition and Action. London: Bradford. 

32.

Thompson, E. (2001a). Empathy and Consciousness. Journal of Consciousness Studies, 8(5-7), 1-

Thompson, E. (Ed.) (2001b). Between Ourselves: Second-Person Issues in the Study of Consciousness. Thorverton: Imprint Academic.

Trevarthen, C., \& Aitken, K. J. (2001). Infant intersubjectivity: research, theory, and clinical applications. Journal of Child Psychology and Psychiatry, 42(1), 3-48.

van Dijk, J., Kopke, M., van Huizen, N., van Uffelen, L., \& Beunk, L. (2019). Empoweringyoung adults on the autistic spectrum: Reframing assistive technology through design. Paper presented at the Proceedings of the 4th Biennial Research Through Design Conference, Delft and Rotterdam, the Netherlands.

https://figshare.com/articles/Empowering_young_adults_on_the_autistic_spectrum_Reframi ng_assistive_technology_through_design/7855907

Varela, F. J. (1979). Principles of Biological Autonomy. New York: Elsevier (North Holland).

Varela, F. J., Thompson, E., \& Rosch, E. (1991). The Embodied Mind: Cognitive Science and Human Experience. Cambridge, MA: MIT Press.

Velez, E., \& Tuana, N. (2020). Editors’ Introduction: Tango Dancing with María Lugones: Toward Decolonial Feminisms. Critical Philosophy of Race, 8(1-2), 1-24. doi:10.5325/critphilrace.8.1-2.0001

Vine Foggo, R. S., \& Webster, A. A. (2017). Understanding the social experiences of adolescent females on the autism spectrum. Research in Autism Spectrum Disorders, 35, 74-85. doi:https://doi.org/10.1016/j.rasd.2016.11.006

Walker, N. (27 September 2017). Neurodiversity: Some Basic Terms \& Definitions. Retrieved from https://neurocosmopolitanism.com/neurodiversity-some-basic-termsdefinitions/

Welch, S. (2019). The Phenomenology of a Performative Knowledge System. Dancing with Native American Epistemology: Palgrave Macmillan.

Williams, Gemma L. 2020. "From Anonymous Subject to Engaged Stakeholder: Enriching Participant Experience in Autistic-language-use Research.” Research for All, 4(2) (see also OSF Preprints. June 2. doi:10.31219/osf.io/wa2dr)

Woods, R., Milton, D., Arnold, L., \& Graby, S. (2018). Redefining Critical Autism Studies: a more inclusive interpretation. Disability \& Society, 33(6), 974-979. doi:10.1080/09687599.2018.1454380

Yergeau, M. (2015). Occupying autism: Rhetoric, involuntarity, and the meaning of autistic lives. In P. Block, D. Kasnitz, A. Nishida, \& N. Pollard (Eds.), Occupying Disability: Critical Approaches to Community, Justice, and Decolonizing Disability (pp. 83-96). Springer: Springer.

Yergeau, M. (2018). Authoring Autism: On Rhetoric and Neurological Queerness: Duke University Press.

Zhang, J., Wheeler, J. J., \& Richey, D. (2006 ). Cultural validity in assessment instruments for children with autism from a Chinese cultural perspective. International Journal of Special Education, 21(109-14).

Zlatev, J., Racine, T. P., Sinha, C., \& Itkonen, E. (2008). The Shared Mind. Perspectives on Intersubjectivity. Amsterdam/Philadelphia: John Benjamins. 